\title{
Marketing Implications of Information Processing: Literature Review and Directions for Future Research
}

\author{
Ruchika Sachdeva
}

\begin{abstract}
Information processing is a series of activities by which stimuli are perceived, transformed into information, and stored (Best et al., 2003). The theory of information processing is becoming increasingly popular in today's information rich environments. Surprisingly, in literature there is little research and discussion on the marketing implications of information processing. The present study tries to explore the various studies related to the importance of information processing. The study highlights the marketing implications of information processing on Indian consumer. The objective of this study is to help the marketing managers understand the Indian consumers processing of information. Knowing and analyzing the information processing styles of the target consumers based on the important variables studied in this research, will help marketers design and place their marketing programs most effectively. Based on the literature review the paper proposes few research propositions in understanding of marketing implications of information processing.
\end{abstract}

Keywords: Information Processing, Marketing implications, Exposure, Attention, Involvement level, Memory and Socio-demographic variables.

\section{INTRODUCTION}

Consumer psychologists have long identified the growing importance of consumer information processing in light of the abundance of information available to consumers. popular in today's era of technological revolution. Information processing is also related to both the consumer's cognitive ability and the complexity of the information to be organization research, information processing traces its lineage back to Herbert Simon - a scholar who was mainly concerned with understanding how people solve problems and make decisions. It is worth noting that although Simon's work reflects two distinct information-processing fields (which focused, respectively, on organizations' and individual psychology). We focus on consumer individual psychology (Simon 1955, 1956) and its implications for the marketing managers. We place several boundary conditions on the scope of this study, a necessary restriction given the vast literature that references information processing. We mostly examine information processing in relation to marketing implications.

Revised Manuscript Received on December 05, 2020.

* Correspondence Author

Dr. Ruchika Sachdeva*, Jack Welch College of Business and Technology, Sacred Heart University, Fairfield, CT-USA, Email: ruchika.sachdeva@hotmail.com

(C) The Authors. Published by Blue Eyes Intelligence Engineering and Sciences Publication (BEIESP). This is an open access article under the CC BY-NC-ND license (http://creativecommons.org/licenses/by-nc-nd/4.0/) Information processing theory is becoming increasingly processed (Schiffman \& Kanuak, 2003). In the field of

\section{PURPOSE OF THE STUDY}

The growing ubiquity of information provides unprecedented opportunities (Knippenberg et al., 2015), for marketing managers, but also a key challenge to manage this wealth of available information to most productive ends. The increasing need to deliver the most appropriate product information to various consumer groups in the most cost-effective manner dictates a closer look at the preference for information processing styles (Darley, 1999) of consumers. A large amount of research relevant to information processing has investigated the impact of various factors (regulatory focus, personal control, gender differences, verbal and interactive protocol methods, risk, traditional and electronic word of mouth and when information is difficult to process) influencing consumer information processing by various authors (Coupey \& Demoranville, 1996; Smerecnik et al., 2012; Roy \& Phau, 2014; Schweidel \& Moe, 2014; Byrne \& Worthy, 2015; Chaxel, 2016). There is a considerable amount of recent work also that addresses the importance of information processing. Joesph and Gaba (2020) address the various forms of information processing: gathering, interpretation, and synthesis of information. Blankespoor (2019) highlights the relationship between the market participant information processing and the impact on firms' disclosure choice. Yang et al. (2018), states that in addition to affecting the amount of effort and attention respondents spend, the bounded rationality literature leads us to expect that Prob will influence how consumers process information. However, besides discussing the various aspects and factors influencing information processing no research has been undertaken to explore the marketing implications of information processing to the best of authors' knowledge. Thus, the purpose of this study is to extent the understanding of marketing implications of information processing, which will help media planners and marketers design their marketing strategies and programs effectively. It is therefore not surprising that the marketers have been urged to know the process of information processing. Westbrook (1987) and Dhar and Itamar (1999) explain that it is very important to know the process of information processing both from marketers' point of view as well as from consumers point of view. According to these authors, marketers should analyze the consumer's decision-making process so that they can design and align their marketing strategies as per their target customers. Better knowledge about information processing by consumers will lead to improved marketing decisions.

Published By:

Blue Eyes Intelligence Engineering

\& Sciences Publication

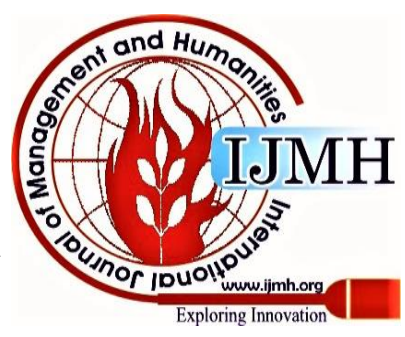


The growth of internet usage in India is increasing and attracting global brands which pose a great challenge for the marketers. According to the Telecom Regulatory Authority India report (T.R.A.I) 2020, numbers of broadband subscribers have reached to 673.39 million. The flow of information explosion through the internet has given an abundance of information to the consumer. According to the U.N. report (2014), by 2020, India is set to become the world's youngest country with $64 \%$ of its population in the working-age group. India has one of the youngest populations in an aging world and by 2022 the median age of India will be just 28 as compared with 37 in China and the US, 45 in Western Europe, and 49 in Japan (Kant, 2019). The educated youth in India constitutes a significant market. With a young, technology-savvy population, improved education, and rapid growth, India is creating a consumer market deeply tied into mobility and connectivity (Bahree, 2016). Brands are developing its presence in social networking sites to meet engagement, brand awareness and word of mouth (Kujur \& Singh, 2017). Consequently, the marketers have to design their promotional programs more effectively supported with strong arguments and justifications for the educated youth. Against this background, it is presumed that an educated Indian youth will get more involved in information processing activities and a study on marketing implications of information processing on Indian consumers will help the marketing managers design their strategies more effectively and efficiently. In the following section, the relevant theoretical background for the various research propositions are reviewed, followed by directions for future research.

\section{LITERATURE REVIEW ON INFORMATION PROCESSING}

In this era of information explosion, the primary and crucial responsibility of marketing managers is to know the information processing process of consumers. Better knowledge about information processing by consumers will lead to improved marketing decisions. Thus, the following section discusses the marketing implications of information processing by highlighting the importance of important variables like exposure, attention, involvement level and memory with information processing. A strong relationship is also explored.

\section{A. Exposure And Information Processing}

Exposure is defined as "putting oneself in a position or situation physically to receive information" (Wheeless, 1974). In this, information and persuasive communication must reach consumers. Once exposure occurs, one or more of the senses are activated and preliminary processing begins. Consumers are often invited to imagine their consumption experiences through exposure to product advertisement (Roy and Phau, 2014), and have to make decisions every day- in a multitude of domains which often have significant consequences (Byrne and Worthy, 2015). Due to rapid globalization and liberalization policies of the Indian government, an Indian consumer has abundance of information and exposure to the global markets. Thus, it is very important to understand how an Indian consumer process information through exposure. of socio demographic variables with information processing

For today's youth the social media and advertising through the electronic word of mouth (eWOM) accelerates exposure impacts because of its extended reach through internet and eliminates the restrictions on time and location (Babić, 2020). Harris and Kalnova (2018) research add to the growing academic literature showing that the young children's exposure to advertising contributes to preferences for the advertised products. Thakur et al. (2017) highlights that packaging plays a great role in the consumer decision making as a package is the face of a product and often is the only product exposure consumers experience prior to purchase. Consequently, distinctive or innovative packaging can boost sales in a competitive environment. Kumar et al. (2014), states that adolescents had more frequent exposure to fast food advertisements, compared to other food/beverage advertising categories, fast food restaurants maintained the highest category share of food and beverage television advertising exposure for adolescents. Thus, an exposure through the right medium plays a great role in the consumer decision making.

A wealth of exposure research has documented that exposure influences the information processing styles. Prior research suggests that exposure to broad versus narrow categorizations in a decision task influence the information processing style (Ulkumen et al., 2010). Individuals differ in their acquisition of information and use of acquired information when making judgements (Childers \& Houston, 1984) and individuals' perception of the information may differ because of different media formats (Darley, 1999). The strength of consumers attitude towards the topic (Petty \& Krosnick, 1995), the various regulatory factors (Higgins, 1997) and type of motivation gained through exposure influences the information processing (Chaiken et al., 1996) of consumers. Level of processing determines the persuasiveness of the message, which influences the person's attitudes and behavior (Pierro et al., 2012). Prior research strongly supports that repetition leads to a positive preference (Lee \& Vakratsas, 2019) and subsequently motivates consumers to gain information about the product. Thus, it is reasonable to presume that the information consumers get through exposure, differ for different consumers in terms of their acquisition, perception and interpretation. Consequently, different type of motivation influences the level of processing and persuasiveness of the message. Thus, extrapolating from the foregoing ideas it is proposed that an individual's capacity and motivation to engage in information processing influence the persuasiveness of the message.

$\mathrm{P}_{1}$ : High (low) persuasiveness of the message is dependent upon high (low) level of consumer's motivation of information processing.

\section{a. Selective Exposure and Information Processing:}

The central theme of selective exposure research has been the hypothesized preference for information consistent with or supportive of the previous choices, commitments, attitudes, or opinions (Wheeless, 1974).

Published By:

Blue Eyes Intelligence Engineering

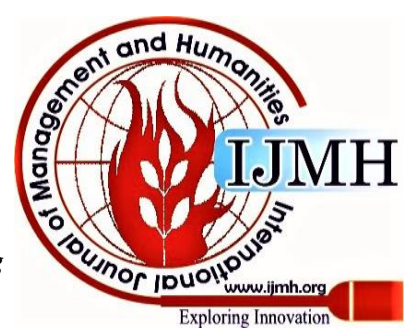


One apparent problem is the definition of what constitutes supportive and reinforcing information, and the other question is what the information supports. The perceived competence of the source is the primary predictor of selective exposure. According to the author, the likelihood of information selection is directly related to its reinforcement or reward strength.

Authors also explain that the selected information support is also problematic. Cotton and Heiser (1980) and Westerwick (2020) proposed and confirmed that when people act on a real, dissonance- producing decision, they seek information supporting that decision and avoid dissonant information. In this paradigm, attitudes (that is attitudinal agreement) are not the predictive agent. Consumers favor attitude consistent messages.

In today's information rich environments consumers are exposed to a large amount of information and are exposed to a large number of stimuli on a more or less random basis during their daily activities. Even if an advertiser is successful at getting his message to the right people at the right time, exposure still may not occur (Blackwell et al., 2003 ; Hawkins et al., 2003). This is because sometimes consumers deliberately try to avoid exposure. The impact of the active self- selecting nature of exposure can be seen in the zipping, zapping and muting of television commercials. Thus, only a limited amount of information could be visually perceived and cognitively processed within a given time frame (Knippenberg et al., 2015). People engage in selective exposure for the information to be processed and choose from messages and exhibit preferences in those selections, which may take the form of a confirmation bias (Camaj, 2019 and Westerwick, 2020). The perception and processing of brand information by the consumers is influenced by prior knowledge or experience (Wheeless, 1974), media perceptions (Darley, 1999) and trust on media (Rumpf et al., 2015). Therefore, it is reasonable to assume that consumers who engage in selective exposure will have low information processing as they rely on their previous choices, information and opinions. Extrapolating from the foregoing ideas, the following proposition is presented: information processing.

\section{b. Overexposure:}

The challenge is no longer to make decisions under conditions of information scarcity; increasingly, it is to make decisions under conditions of information overload (Knippenberg et al., 2015). Information overload occurs when consumers are confronted with so much of information that they cannot or will not attend to all of it (Hawkins et al., 2003). Instead, they become frustrated and either postpone or give up the decision, make a random choice, or utilize a suboptimal portion of the total information available. This information overload is caused because of the overexposure. Loudon and Bitta (2006) state that consumer's information load has traditionally been defined in terms of the number of brands and/or the number of attributes per brand that are available for processing. When a consumer's exposure to an amount of information exceeds his threshold point, it will generate conditions of information overload and an Indian consumer is undoubtedly at a stage of information overload.
$\mathrm{P}_{2}$ : Selective exposure is inversely related to

Overexposure has lot of negative effects and it extends beyond advertising to the product itself. Overexposure might be considered as one of the reasons for the decline in sales of a company. Rumpf (2015) states that more intense media content increases the chance that brand information is not attended to by the consumer (intensity attention assumption) and therefore not remembered (intensity memory assumption). Thus, consumer attention, attraction towards a product is lost because of overexposure. Hence, extrapolating from the foregoing ideas, the following proposition is presented:

$\mathrm{P}_{3}$ : Overexposure has a negative impact on information processing.

\section{B.Attention and Information Processing}

Attention has been conceptualized as a state of alertness or arousal that allows the individual to focus on a selected aspect of the environment, often in preparation for learning or problem solving (Bukatko \& Daehler, 2001). Gaining access to information is not the biggest challenge organizations are facing (Simon, 1957), challenge is of gaining attention. Even if consumers wanted to, it is simply impossible for them to pay attention to all the products and companies frantically waving their hands at them. They are very selective in gaining attention. For these reasons, grabbing the consumers' attention is vital for the marketers today. Rahmani et al. (2020), researched using a generic flocking model, have demonstrated the importance of finite attention capacity of individuals for collective information processing in complex environments. It is widely accepted that high connectivity among individuals facilitates group consensus, and being in a group provides benefits to individuals through social information about the environment provided by other group members. Still the final decision maker is the individual consumer. The amount of information scales faster than the attention of human decision makers who have to make decision about which information has priority, and what will be shunted away (Knippenberg et al., 2015). Voluntary attention is the ability to intentionally attend to something, while reflexive attention describes the phenomena where something, such as a sensory event, captures our attention (Gazzaniga et al., 2002). Consumers will remember the brand information more through voluntary attention than reflexive attention. Limited attention of the decision makers is a concern for marketers. Thus, it is reasonable to presume that consumers with voluntary attention will get more involved in information processing activities than reflexive attention consumers. Extrapolating from the foregoing ideas, the following proposition is presented:

$\mathrm{P}_{4}$ : Voluntary attention has a more positive impact on information processing than reflexive attention.

According to cognitive personality research, consumers differ with respect to their style of information processing and classify consumers as visualizers and verbalizers (Childers et al., 1985), whereas visualizers prefer visual information, verbalizers prefer written or verbal information.

Published By:

Blue Eyes Intelligence Engineering

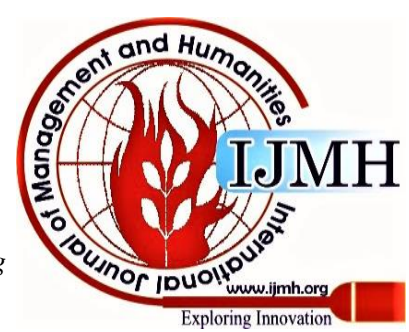


A propensity towards verbal or visual processing reveals itself at an attention phase (Darley, 1999) and it is reflected by a propensity to attend to one type of stimuli over another. Individuals differ in their acquisition of information and use of acquired information when making judgements (Childers \& Houston, 1984). Both visualizers and verbalizers are considered as one of the most powerful mediating variables for consumption related information by consumers (Rossiter \& Percy, 1978) and positivity towards a medium helps consumers to trust and limit their attention and exposure to that medium. Visualizers hold positive/favorable perceptions about television medium than their verbalizer's counterparts and verbalizers hold positive /favorable perceptions about print media than their visualizer's counterpart (Darley, 1999). So, it is reasonable to propose that both visualizers and verbalizers style of information processing effects the attention phase of consumers. Against this background it is reasoned that visualizer's style of information processing through television media will have a positive impact on attention and verbalizers style of positive impact on attention. Extrapolating from the foregoing ideas, the following propositions are presented:

$\mathrm{P}_{5}$ : Visualizers information processing style has a more positive impact on attention through television media.

$\mathrm{P}_{6}$ : Verbalizers information processing style has a positive impact on attention through print media.

\section{Involvement Level and Information Processing}

Consumer's attention process of the stimuli is largely dependent on the level of involvement. Involvement is the level of perceived personal importance and/ or interest evoked by a stimulus within a specific situation (Blackwell et al., 2003). The degree of personal involvement is a key factor in shaping the type of decision process that consumer's follow (Tai \& Chang, 2005). To the extent it is present, the consumer acts with deliberation to minimize the risks and to maximize the benefits gained from purchase and use. The involvement ranges from low to high. For marketers to understand the Indian consumers involvement process is very crucial, as today's Indian consumer is bombarded with loads of information and product knowledge. A large amount of research on motivations for consumers to get more involved has investigated that the involvement increases with a congruence with recipient's personal value and between values and framing of messages; and adds value and message framing to the growing list of factors that impact message processing (Borgstede et al., 2014). Consumers desire to defend ones existing attitudes, beliefs and behaviors to keep everything in its place (Chaiken \& Eagly, 1989; Hart et al., 2009), act as the greatest motivator for the consumers to be highly involved. This leads us to conclusion that when the message is congruent, it is highly involving and thus consumers engage in systematic processing (Johnson \& Eagly, 1989) of the information. Systematic processing of the information involves high motivation for an effortful thinking and heuristic processing of information involves less motivation for an effortful thinking (Petty \& Cacioppo, 1986; Eagly \& Chaiken, 1993). An affect heuristic could be lessened or eliminated when the intensity of cognitive evaluations is stronger (Su et al., 2010). Consequently, information processing though print media will have a

marketers should analyze that those consumers who follow the central route (systematic processing) for processing of information will support and expect strong strength of arguments in the message (Petty \& Cacioppo, 1986; Borgstede et al., 2014) than consumers who follow heuristic route. Thus, it is reasonable to propose that high involvement leads to systematic processing only when the message is in congruence with the consumers. Low involvement leads to heuristic processing only when the message is not in congruence with the consumers. Extrapolating from the foregoing ideas, the following propositions are presented:

$\mathrm{P}_{7}$ : High involved consumers engage in systematic processing of the congruent information.

$\mathrm{P}_{8}$ : Low involved consumers engage in heuristic processing of the incongruent information.

\section{Memory and Information Processing}

Recently marketing literature has seen a substantial interest in the study of consumer memory. A robust research done on the literature of consumer memory depicts the various factors [ mood, sources of information, pleasant scents, different types of advertising, humor, literacy, social context, pricing strategies, context intensity and background music] studied in conjunction with consumer memory by various authors [Baron, 2003; Morrin \& Ratenshwar, 2003; Madhubalan et al., 2009; Jeong et al., 2011; Reichhart, 2012; Ketling \& Rice, 2013; Susan et al., 2014; Kutlu, 2015 ; Gianlungi et al., 2016]. Yet, to the author's knowledge, no previous research has explored the relationship of consumer memory with information processing on Indian consumers. Processing of the information is done by the consumers based on the information stored in their memory. Memory is also considered as a key measure of advertising and marketing success and its effectiveness (Susan et al., 2014). Memory recall is significantly related to processing preference (Richardson, 1978). Both recall and recognition memory aids brand recall (Solomon, 2004). High perception and processing of brand information by the consumer is influenced by felt arousal (Pham, 1992), relevant stimuli (Kane et al., 2001), cognitive ability, stimulus characteristics (Baron, 2003 and Schiffman \& Kanuak, 2003), memory capacity (Unsworth, 2007) and excitement or intensity of media (Rumpf et al., 2015). The propensity towards working memory phase is reflected by a propensity to form mental representations of certain cues of information processing (Heckler et al., 1993) and individuals also differ in terms of imagery i.e. their ability to form mental images and these differences influence their ability to recall information (Gerald \&Terry, 1999).

Working memory has effect on information processing of consumers and, thus, their subsequent actions. The mental representation of the cues is represented by the visual perceptions of the stimulus/ information. Consequently, visual perceptions of the information by the consumer effect the cognitive processing of brand information in memory.

Published By:

Blue Eyes Intelligence Engineering

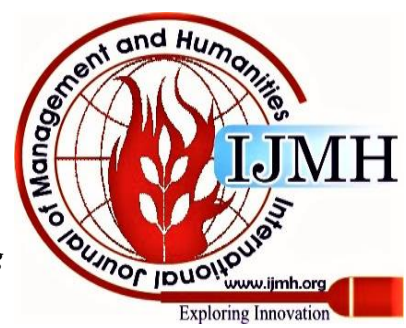


Consumers will process only those brand- related stimuli, which they already attended (Lachter et al., 2004), and have visual perceptions, as only those stimuli get a chance to access the memory. Thus, it is reasonable to propose that mental representations effect the processing of the information and marketing managers are naturally interested in analyzing the visual perception of the stimulus as it is an essential pre-requisite for long term effects on memory. Extrapolating from the foregoing ideas, the following proposition is presented:

$\mathrm{P}_{9}$ : Visual perception of the information in the memory has a positive impact on information processing.

\section{E. Socio Demographic Factors and Information Processing}

In marketing literature an association has long been made between socio demographic variables and information processing. The way in which a decision-making situation is contextualized influences the information processing styles individuals utilize (Slovic \& Lichtenstein, 1983). There is a gender difference in information processing styles during decision making (Byrne \& Worthy, 2015) and gender differences during decision making have also been attributed to differences in information processing (Van et al., 2013). Various findings suggest that women are less risk - seeking than males (Powell \& Ansic, 1997; Jianakoplos \& Bernasek, 1998; Croson \& Gneezy, 2009) women attend to more detailed information than men (Meyers, 1989; Meyers \& Maheswaran, 1991; Darley \& Smith, 1995; Cahill, 2006; Andreano \& Cahill, 2009) and women elaborate more on various aspects of media than men (Holbrook, 1986 and Darley, 1999). Thus, it is reasonable to propose that women are more involved in information processing activities in comparison to men. Extrapolating from the foregoing ideas, the following proposition is presented:

$\mathrm{P}_{10}$ : Women have a more positive impact on information processing than men.

Various authors (Newman \& Newman, 1999; Bukatko \& Daehler, 2001; Rosenzweig et al., 2002; Baron, 2003) have discussed the impact of age on information processing. Information processing abilities are different in people belonging to different age groups. Processing of information increases with an age. With increasing age, the processing speed, recall and recognition memory, rehearsal strategy, meta memory and growth of general knowledge all increases. Thus, to conclude that processing, retrieval of information is slow in young children; the age group of early adulthood and middle adulthood is characterized by many responsibilities; and later adulthood, and very old age is characterized by memory loss. So, the marketing managers have to design their marketing programs differently for a different age group for the most effective processing of the information.

Thus, it is reasonable to conclude that the cognitive processing capability of consumers is dependent upon different age group. Involvement levels will be high if the information is in congruence with the specific age group. So, marketers should design the marketing programs in congruence with the specific age groups to get effective results. Extrapolating from the foregoing ideas, the following proposition is presented: processing.

$\mathrm{P}_{11}$ : Age has a positive impact on information

Table 1 summarizes the various propositions explored in this study. The various variables studied with information processing are mentioned along with the study reviewed.

Table 1. Various propositions proposed in the study.

\begin{tabular}{|c|c|c|}
\hline $\begin{array}{l}\text { Variables } \\
\text { Studied }\end{array}$ & Propositions & Literature Review \\
\hline Exposure & \multirow[b]{2}{*}{$\begin{array}{l}\mathrm{P}_{1} \text { High (low) } \\
\text { persuasiveness of } \\
\text { the message is } \\
\text { dependent upon high } \\
\text { (low) level of } \\
\text { consumer's } \\
\text { motivation } \\
\text { information } \\
\text { processing. }\end{array}$} & \multirow[b]{2}{*}{$\begin{array}{l}\text { Childers \& Houston, } \\
\text { 1984; Chaiken et al., } \\
\text { 1996; Darley, 1999; } \\
\text { Pierro et al., 2012; } \\
\text { Lee \& Vakratsas, } \\
2019 .\end{array}$} \\
\hline $\begin{array}{l}\text { High (Low) } \\
\text { Persuasivene } \\
\text { ss of } \\
\text { message }\end{array}$ & & \\
\hline $\begin{array}{l}\text { Selective } \\
\text { exposure }\end{array}$ & $\begin{array}{l}\mathrm{P}_{2}: \quad \text { Selective } \\
\text { exposure is inversely } \\
\text { related to } \\
\text { information } \\
\text { processing. }\end{array}$ & $\begin{array}{l}\text { Wheeless, 1974; } \\
\text { Cotton \& Heiser, } \\
\text { 1980; Blackwell et } \\
\text { al., } 2003 \text {; } \\
\text { Knippenberg et al., } \\
\text { 2015; Rumpf et al., } \\
\text { 2015; Camaj, 2019; } \\
\text { Westerwick, 2020. }\end{array}$ \\
\hline $\begin{array}{l}\text { Over } \\
\text { Exposure }\end{array}$ & $\begin{array}{lr}\mathrm{P}_{3}: & \text { Overexposure } \\
\text { has a } & \text { negative } \\
\text { impact } & \text { on } \\
\text { information } & \\
\text { processing } & \end{array}$ & $\begin{array}{l}\text { Hawkins et al., } \\
\text { 2003; Loudon \& } \\
\text { Bitta, } \\
\text { Knippenberg et al., } \\
\text { 2015; Rumpf et al., } \\
\text { 2015. }\end{array}$ \\
\hline Attention & & \\
\hline $\begin{array}{l}\text { Voluntary } \\
\text { and } \\
\text { Reflexive } \\
\text { attention }\end{array}$ & $\begin{array}{l}\mathrm{P}_{4} \text { : Voluntary } \\
\text { attention has a more } \\
\text { positive impact on } \\
\text { information } \\
\text { processing than } \\
\text { reflexive attention. }\end{array}$ & $\begin{array}{l}\text { Gazzaniga et al., } \\
\text { 2002; Knippenberg } \\
\text { et al., } 2015 \text {; } \\
\text { Rahmani et al., } \\
\text { 2020. }\end{array}$ \\
\hline $\begin{array}{l}\text { Visualizers } \\
\text { and } \\
\text { Verbalizers }\end{array}$ & $\begin{array}{l}\mathrm{P}_{5} \text { : Visualizers } \\
\text { information } \\
\text { processing style has } \\
\text { a more positive } \\
\text { impact on attention } \\
\text { through television } \\
\text { media. } \\
\mathrm{P}_{6} \text { : Verbalizers } \\
\text { information } \\
\text { processing style has } \\
\text { a more positive } \\
\text { impact on attention } \\
\text { through print media. }\end{array}$ & $\begin{array}{l}\text { Rossiter \& Percy, } \\
\text { 1978; Childers et al., } \\
\text { 1985; Darley, } 1999 .\end{array}$ \\
\hline
\end{tabular}

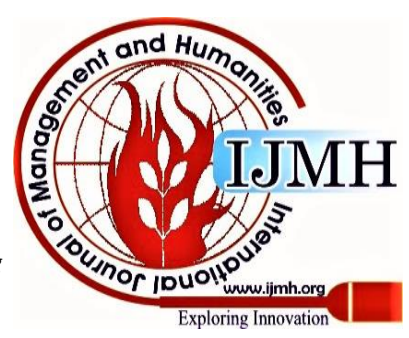




\begin{tabular}{|c|c|c|}
\hline $\begin{array}{l}\text { Involvemen } \\
\text { t Level }\end{array}$ & $\begin{array}{l}\mathrm{P}_{7} \text { : High involved } \\
\text { consumers engage in } \\
\text { systematic } \\
\text { processing of the } \\
\text { congruent } \\
\text { information. } \\
\text { P }_{8} \text { Low involved } \\
\text { consumers engage in } \\
\text { heuristic processing } \\
\text { of the incongruent } \\
\text { information. }\end{array}$ & $\begin{array}{l}\text { Petty \& Cacioppo, } \\
\text { 1986; Johnson \& } \\
\text { Eagly, 1989; Eagly } \\
\text { \& Chaiken, 1993; } \\
\text { Borgstede et al., } \\
\text { 2014. }\end{array}$ \\
\hline Men & $\begin{array}{l}\text { P9: } \\
\text { Visual } \\
\text { perception of the } \\
\text { information in the } \\
\text { memory has a } \\
\text { positive impact on } \\
\text { information } \\
\text { processing. }\end{array}$ & $\begin{array}{l}\text { Heckler et al., 1993; } \\
\text { Gerald \& Terry, } \\
\text { 1999; Lachter et al., } \\
\text { 2004. }\end{array}$ \\
\hline $\begin{array}{l}\text { Socio-demo } \\
\text { graphic } \\
\text { Gender }\end{array}$ & $\begin{array}{l}\mathrm{P}_{10} \text { : Women have a } \\
\text { more positive impact } \\
\text { on information } \\
\text { processing than } \\
\text { men. }\end{array}$ & $\begin{array}{l}\text { Meyers \& } \\
\text { Maheswaran, 1991; } \\
\text { Darley \& Smith, } \\
\text { 1995; Darley, 1999; } \\
\text { Andreano \& Cahill, } \\
\text { 2009; Van et al., } \\
\text { 2013; Byrne \& } \\
\text { Worthy, 2015. }\end{array}$ \\
\hline Age & $\begin{array}{l}\mathrm{P}_{11}: \text { Age has a } \\
\text { positive impact on } \\
\text { information } \\
\text { processing }\end{array}$ & $\begin{array}{l}\text { Newman } \& \\
\text { Newman, } 1999 ; \\
\text { Bukatko \& Daehler, } \\
\text { 2001; Rosenzweig et } \\
\text { al., } 2002 \text { \& Baron, } \\
\text { 2003. }\end{array}$ \\
\hline
\end{tabular}

\section{DIRECTIONS FOR FUTURE RESEARCH}

Various propositions have been put forth in this study that needs to be empirically tested by future researchers. There are more issues related to information processing that needs to be researched and discussed. The perception of information is also dependent upon the medium the consumers trust the most (Darley, 1999). The exposure to a trusted medium is more as compared to others for a consumer. So, future researchers could explore the relationship of trust with exposure. This will help to activate the consumer mindset in the right direction and influence information processing.

Future researchers could explore the relationship of selective exposure with brand extension and how it influences the information processing. How information processing of consumers is affected when established and preferred brand names go for an extension? Will consumers have a positive selective exposure with preferred brand extension? Information overloads effects consumers and organizations simultaneously. Future researchers could design effective strategies on how to handle information overload? More research could be done to analyze how consumers categorize and integrate this overloaded information to create new, relevant, and meaningful information. The research is also needed by organizations to search for the most relevant information to be shared with consumers and what information to withhold. The organization dissemination of information to consumers must require robust network ties based on trust (Knippenberg et al., 2015). Information today is not limited by geographical boundaries. Social media is achieving increasing importance as a channel for consumer's online participation and engagement (Kujur \& Singh, 2017). Today, the sharing of information with remote places is very accessible through social media. Chong (2003) explored the concept of trust and culture among the online shoppers but the future researchers could explore the impact of social media on different information processing styles. So, research could be conducted on information processing and social media or social media could also be one of the variables for studying the impact of information processing and its implications for the marketers. Future researchers could study the impact of intrinsic cues (such as size, shape, and grade of ingredients) and extrinsic cues, (packaging characteristics, advertising messages, statements of friends, and other sources of information) influencing information processing.

\section{MANAGERIAL IMPLICATIONS OF THE STUDY}

This study on marketing implications of information processing will help Indian marketing managers in designing their marketing strategies more effectively. The present study tries to highlight the important variables that influence the information processing of Indian consumers. The designing of marketing strategies based on the important variables studied in this research will help the marketing managers achieve their sales targets and other results as expected from their marketing strategies. As per the study of this research, it is very important for an Indian marketing manager to understand that India constitutes the world's youngest population and the educated youth of India is globally connected through the internet. Consequently, marketers have to design their marketing strategies most effectively and efficiently based on strong arguments and justifications. Managers have to understand that exposure and the right medium of exposure influences the information processing of consumers. Consumer's motivation, attitude, and perception about a specific medium of exposure should be the basis of segmentation before designing any promotional campaigns.

Consumers confronted with overexposure and selective exposure should be characterized differently and different promotional campaigns should be designed for them.

In this era of information overload, the utmost concern of managers is to gain the attention of the target consumers. Segmenting the consumers with respect to their style of information processing i.e. verbal or visual processing before designing any promotional campaigns will help managers gain the attention of target consumers. Subsequently, an increase in attention will lead to an increase in involvement level and ultimately will result in buying the product.

Published By:

Blue Eyes Intelligence Engineering

\& Sciences Publication

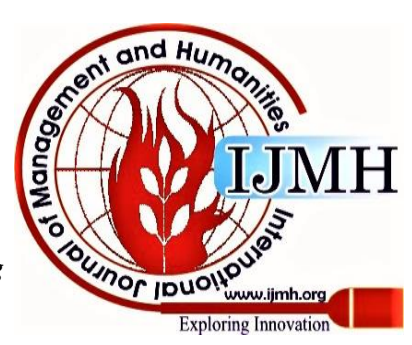


Designing a marketing campaign based on age and gender will positively influence the information processing of consumers and will leave a long-lasting impact on memory. As stated above the enhanced knowledge about information processing by consumers will lead to improved marketing strategy decisions of managers.

\section{CONCLUSION}

The study will help the marketers understand the information processing process more precisely from the marketer's perspective. The different stages of information processing exposure, attention, involvement level, memory, are explored and various propositions are derived from review of literature. For handling the intense competition in the market, the marketing managers have to design powerful competitive strategies for gaining a competitive edge.

\section{REFERENCES}

1. Andreano, J. M., \& Cahill, L. (2009). Sex Influences on the Neurobiology of Learning and Memory. Learning \& Memory, 16(4), 248-266.

2. Babić, Rosario. A., De, Valck. K., \& Sotgiu, F. (2020) Conceptualizing the electronic word-of-mouth process: What we know and need to know about eWOM Creation, Exposure, and Evaluation. Journal of the Academy of Marketing Science, 48, 422-448.

3. Bahree, Megha. (2016). The Indian Consumer Market will be Huge, But Will be Very Different from China's: Report. Retrieved from http://www.forbes.com/sites/meghabahree/2016/06/02/the-indian-con sumer-market-will-be-huge-but-very-different-from-chinas-report/\#33 1fd5807aa4.

4. Baron, A. R. (2003). Memory of Things Remembered and Forgotten. Psychology, Pearson Education (Singapore) Pvt. Ltd., 208-244.

5. Best, J. R., Hawkins, D. I., \& Coney, A. K. (2003). Perception. Consumer Behaviour Building Marketing Strategy, Tata McGraw Hill Publishing Company Ltd., 284-313.

6. Blackwell, R., Miniard. D., Paul. W., \& Engel, J, F. (2003). The Consumer Decision Process. Consumer Behaviour, Vikas Publishing House Pvt. Ltd., 67-95.

7. Blankespoor, Elizabeth. (2019). The Impact of Information Processing Costs on Firm Disclosure Choice: Evidence from the XBRL Mandate. Journal of Accounting Research, 57(4), 919-967.

8. Borgstede, C. V., Anderson, M., \& Hansla, A. (2014). Value-congruent Information Processing: The role of issue involvement and argument strength. Basic and Applied Social Psychology, 36, 461-477.

9. Bukatko, D., \& Daehler, W. M. (2001). Cognition: Information Processing. Child development: A Thematic Approach, Fourth edition, Houghton Miffin Company, 302-337.

10. Byrne, K. A., \& Worthy, D. A. (2015). Gender differences in reward sensitivity and information processing during decision-making. Journal of Risk Uncertain, 50, 55-71.

11. Cahill, L. (2006). Why sex matters for neuroscience. Nature Neuroscience Reviews, 7, 477-484.

12. Camaj, Lindita. (2019). From Selective Exposure to Selective Information Processing: A Motivated Reasoning Approach. Media and Communication, 7(3), 8-11.

13. Chaiken, S., \& Eagly, A. H. (1989). Heuristic and Systematic Information Processing Within and Beyond the Persuasion Context.

14. Chaiken, S., Giner - Sorolla, R., \& Chen, S. (1996). Beyond accuracy: Defense and Impression Motives in Heuristic and Systematic Information Processing. In P.M. Golluritzer, \& J.A. Bargh (Eds). The psychology of action: Linking motivation and Cognition to Behavior (pp 212-252). New York, NY: Guilford.

15. Chaxel, A. S. (2016). Why, When and How Personal Control Impacts Information Processing: A Framework. Journal of Consumer Research, Vol 43, 179-197.

16. Childers, T.L., \& Houston, M.J. (1984). Conditions for a Picture -Superiority Effect on Consumer Memory. Journal of Consumer Research, 11, 643-54.

17. Childers, T.L., Houston, M.J., \& Heckler, S.E. (1985). Measurement of Processing. Journal of Consumer Research, 12, 125-133. New York: Guilford Press, 212-52. Individual Differences in Visual Versus Verbal Information

18. Chong, Bessie. (2003). Why culture matters for the formation of consumer trust? A conceptual study of barriers for realizing real global exchange in Hong Kong. Asia Pacific Management Review, 8(2), 217-240.

19. Cotton, J. L., \& Hieser, R.A. (1980). Selective Exposure and Cognitive Dissonance. Journal of Research in Personality, 14, 518-527.

20. Coupey, E., \& Demoranville, C.W. (1996). Information Processability and Restructuring: Consumer Strategies for Managing Difficult Decisions. Advances in Consumer Research, Vol 23, 225-230.

21. Croson, R., \& Gneezy, U. (2009). Gender Differences in Preferences. Journal of Economic Literature, 47, 448-598.

22. Darley, W. K. (1999). The Moderating Influence of style of Information Processing on Media Perceptions and Information Exposure. Journal of Marketing Communications, 189-194.

23. Darley, W.K., \& Smith, R.E. (1995) Gender Differences in Information Processing strategies: An Empirical test of the Selectivity Model in Advertising Response. Journal of Advertising, 24, 41-56.

24. Dhar, R., \& Itamar, S. (1999). Making Complementary Choices in Consumption Episodes: Highlighting Versus Balancing. Journal of Marketing Research, Vol. XXXVI (February), 29-44.

25. Eagly, A., \& Chaiken, S. (1993). The psychology of Attitudes. Orlando, FL: Harcourt Brace.

26. Gazzaniga, S. M., Ivry, S. R., \& Mangun, R. G. (2002). Selective Attention and Orienting. Cognitive Neuroscience: The Biology of the Mind, W.W. Norton \& Company, 244-300.

27. Gerald, H., \& Terry, E. (1999). The Impact of Congruity between Brand Name and Country of Production on Consumers Product Quality Judgments. International Journal of Research in Marketing, Vol. 16, 199-215.

28. Gianluigi, G., Alessandro, M. P., Antonio, M., Mauro, C., Luco, C., \& Purpaolo, P. (2016). Effects of Background Music Endings on Consumer Memory in Advertising. International Journal of Advertising, 35(3), 504-518.

29. Harris, Jennifer. L., Kalnova, Svetlana. S., (2018). Food and beverage TV advertising to young children: Measuring Exposure and Potential Impact. Appetite 123, 49-55.

30. Hart, W., Dolores, A., Alice, H.E., Inge, B., Matthew, J. L., \& Lisa, M. (2009). Feeling Validated versus Being Correct: A Meta-Analysis of Selective Exposure to Information. Psychological Bulletin, 135 (4), 555-88.

31. Hawkins, L. D., Best, J. R., \& Coney, A. K. (2003). Perception. Consumer Behaviour: Building Marketing Strategy. Tata-McGraw Hill, 282-316.

32. Heckler, S.E., Childers, T.L. \& Houston, M.J. (1993). On the Construc Validity of the SOP Scale. Journal of Mental Imager, 17, 119-132.

33. Higgins, T. E. (1997). Beyond Pleasure and Plain. American Psychologist, 52(12), 1280-1300.

34. Holbrook, M.B. (1986). Aims, Concepts, and Methods for Representation of Individual Differences in Esthetic Responses to Design Features. Journal of Consumer Research, 11,728-39.

35. Jeong, Yongick., Kim, Yeuseung., \& Zhao, Xinshu. (2011). Competing for Consumer memory in Television Advertising: An empirical examination of the impacts of non-editorial clutter on brand memory in mega-event broadcasts. International. Journal of Advertising, 30(4), 617-640.

36. Jianakoplos, N. A., \& Bernasek, A. (1998). Are Women More Risk Averse? Economic Inquiry, 36, 620-630.

37. Johnson, B.T., \& Eagly, A.H. (1989). Effects of Involvement on Persuasion: A meta-analysis. Psychology. Bulletin, 106, 290-314.

38. Joseph, John., \& Gaba, Vibha. (2020). Organizational Structure, Information Processing, and Decision-Making: A Retrospective and Road Map for Research. Academy of Management Annals, 14 (1), 267-302.

39. Kane, M.J., Bleckley, M.K., Conway, A.R.A., \& Engle, R.W. (2001). A controlled-attention view of working memory capacity: Individual Differences in Memory Span and the Control of Visual Orienting. Journal of Experimental Psychology: General, 130, 169-183.

40. Kant, Ravi. (2019). Youth Demographic is key to India's Future. Retrieved

from https://asiatimes.com/2019/04/india-17th-general-election-a-choice-be tween-demographic-dividend-and-democratic-disaster/

Published By:

Blue Eyes Intelligence Engineering

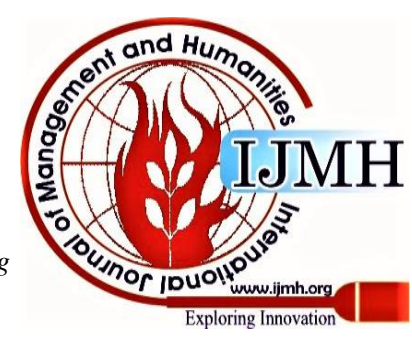


41. Kelting, K., \& Rice, D. H. (2013). Should we hire David Beckham to endorse our Brand? Contextual Interference and Consumer Memory for Brands in a Celebrity's Endorsement Portfolio. Psychology, Vol 30 (7), 602-613

42. Knippenberg, D. V., Dahlander, L., Haas, M. R., \& George, G. (2015). Information, Attention and Decision Making. Academy of Management Journal, 58 (3), 649-657.

43. Kujur Fedric, Singh Saumya (2017). Engaging Customers through Online Participation in Social Networking Sites. Asia Pacific Management Review, 22, 16-24.

44. Kumar, Gayathri., Zytnick, Deena., Onufrak, Stephen., Harris, Jennifer. L., Wethington, Holly., Kingsley, Beverly., \& Park, Sohyun., (2014). Caregiver and Adolescent Responses to Food and Beverage Marketing Exposures Through an Online Survey. Childhood Obesity, 10(1), 64-71.

45. Kutlu, L. (2015). Limited Memory Consumers and Price Dispersion. Review of Industrial Organization, 46(4), 349-357.

46. Lachter, J., Forster, K.I. \& Ruthruff, E. (2004). Forty-five years after Broadbent (1958). Still No Identification Without Attention. Psychological Review, 111, 880-913.

47. Lee, June. Soo., \& Vakratsas, Demetrios. (2019). Dynamic Asymmetric Effects of Cross media Exposures over the Purchase Cycle in China, TV Ads Benefit from Prior Online Exposure, but Not Vice-Versa. Journal of Advertising Research, 455-465.

48. Loudon, L. D., \& Bitta, D. J. (2006). Information Processing. Consumer Behaviour, IV Edition Tata McGraw-Hill.

49. Madhubalan, V., Carlos, J., Lan, Xia., \& Roland, G. (2009). Understanding the Influence of Literacy on Consumer Memory: The Role of Pictorial Elements. Journal of Consumer Psychology, Vol 19, Issue 3, 389-402.

50. Meyers-Levy, J. (1989) Gender differences in information processing: a selectivity interpretation. In P.Cafferata and A.M. Tybout (eds) Cognitive and Affective Responses to Advertising. Lexington,MA:Lexignton Books, pp.219-60.

51. Meyers-Levy, J., \& Maheswaran, D. (1991). Exploring Differences in Males and Females Processing Strategies. Journal of Consumer Research, 18, 63-70.

52. Morrin, M., \& Rathneshwar, S. (2003). Does it Make Sense to use Scents to Enhance Brand Memory? Journal of Marketing Research Vol XL (February), 10-25.

53. Newman, M. B., \& Newman, R. P. (1999). Development Through Life Seventh Edition. An International Thomson Publishing Company.

54. Petty, R.E., \& Cacioppo, J.T. (1986). Communication and persuasion: Central and peripheral routes to persuasion. New York, NY: Springer-Verlag

55. Petty, R.E., \& Krosnick, J.A. (1995). Attitude Strength: Antecedents and consequences. Hillsdale, N.J : Lawrence Erebaum Associates.

56. Pham, M.T. (1992). Effects of Involvement, Arousal and Pleasure on the Recognition of Sponsorship Stimuli. Advances in Consumer Research, 19, 85-93.

57. Pierro, A., Mannetti, L., Kruglanski, A. W., Klein, K., \& Orehek, E. (2012). Persistence of Attitude Change and Attitude - Behavior Correspondence based on Extensive Processing of Source Information. European Journal of Social Psychology, 42, 103-111.

58. Powell, M., \& Ansic, D. (1997). Gender differences in Risk Behaviour in Financial Decision-Making: An Experimental Analysis. Journal of Economic Psychology, 18(6), 605-628.

59. Rahmani, Parisa., Peruani, Fernando., \& Romanczuk, Pawel. (2020) Flocking in Complex Environments-Attention Trade-offs in Collective Information Processing. PLoS Computational Biology, 16 (4), 1-18.

60. Reichhart, P. (2012). Analyzing the effects of Mobile Advertising on Consumer's Memory. International Journal of Electronic Business,10(2), 101-119.

61. Richardson, J.T.E. (1978). Mental Imagery and Memory: Coding Ability or Coding Preference. Journal of Mental Imagery, 2(1), 101-115.

62. Rosenzweig, R. M., Breedlove, S. M., \& Leiman, L. A. (2002). General Principles of Sensory, Processing, Touch and Pain. Biological Psychology, Sinauer Associates Inc. 315-317.

63. Rossiter, J.R. and Percy, L. (1978) Visual imagining ability as a mediator of advertising response. Advances in Consumer Research, 5 , 621-9.

64. Roy, R., \& Phau, I. (2014). Examining Regulatory Focus in the Information Processing of Imagery and Analytical Advertisements. American Academy of Advertising, 43(4), 371-381.
65. Rumpf, C., Noel, B., Breuer, C., \& Memmert, D. (2015). The Role of Context Intensity and Working Memory Capacity in the Consumer's Processing of Brand Information in Entertainment Media. Psychology \& Marketing, Vol 32(7), 764-770.

66. Schiffman, G. L., \& Kanuk, L. L. (2003). Consumer Learning. Consumer Behaviour, VIII edition, 226-32.

67. Schweidel, D.A., \& Moe, W. W. (2014). Listening in on social media: A joint model of sentiment and venue format choice. Journal of Marketing Research, 51(4), 387-402.

68. Simon, H. A. (1955). A Behavioral Model of Rational Choice. The Quarterly Journal of Economics, 69(1), 99-118.

69. Simon, H.A. (1956). Rational choice and the structure of the environment. Psychological Review, 63(2), 129.

70. Simon, H.A. (1957), Models of Man: Social and rational New York, Wiley.

Slovic, P., \& Lichtenstein, S. (1983). Preference Reversals: A Broader Perspective. American Economic Review, 73, 590-605.

72. Smerecnick, C. M.R., Mesters, I., Candel, Math. J.J.M., Vries, H. D., \& Vries, N. K. D. (2012). Risk Perception and Information Processing: The Development and Validation of a Questionnaire to Assess self-reported Information Processing. Risk Analysis, 32(1), 54-66.

73. Solomon, R. M. (2004). Consumer Behaviour, buying. Learning and Memory, Prentice Hall, Second Edition, 99-129.

74. Su, Hung-Jen., Chang, Chia-Jung., Chuang, Shih-Chieh. (2010). The Effect of Corporate Image as an Affect Heuristic on Investors' Decision Making. Asia Pacific Management Review, 15(3), 453-476.

75. Susan, E. H., Kevin, L. K., Michael, J., \& Houston, J. A. (2014) 'Building Brand Knowledge Structures: Elaboration and Interference Effects on the Processing of Sequentially Advertised Brand Benefit Claims. Journal of Marketing Communications, 20 (3), 176 -196.

76. Tai, Hsuan-Ting., \& Chang, Shao-Shiun. (2005). The Causal Model of Internet Advertising Effectiveness. Asia Pacific Management Review,10(1), 78-92.

77. Telecom Regulatory Authority of India Report (2020). Retrieved from:https://www.trai.gov.in/sites/default/files/PR_No.29of2020.pdf

78. Thakur, Pankaj., Mehta, Piyush., \& Gupta, Nikhil. (2017). An Impact Study of Food Product Packaging on Consumer Buying Behaviour: A Study Premise to Himachal Pradesh-India, International Journal of Bio-resource and Stress Management, 8(6), 882-88.

79. Ulkumen, G., Chakravarti, A., \& Morwitz, V. G. (2010). Categories Create Mind-Sets: The Effect of Exposure to Broad Versus Narrow Categorizations on Subsequent, Unrelated Decisions. Journal of Marketing Research, Vol XLVII (August), 659-671.

80. United Nations Report (2014), The Hindu. Retrieved from URL: http://www.thehindu.com/todays-paper/tp-in-school/india-has-worldslargest-youth-population-un-report/article6612615.ece.

81. Unsworth, N. (2007). Individual Differences in Working Memory Capacity and Episodic Retrieval: Examining the Dynamics of Delayed and Continuous Distractor Free Recall. Journal of Experimental Psychology: Learning, Memory and Cognition, 33, 1020-1034.

82. Van, D. B., Homberg, J., \& De, V. L. (2013). A Critical Review of Sex Differences in Decision-Making Tasks: Focus on the Iowa Gambling Task. Behavioural Brain Research, 238(1), 95-108.

83. Westbrook, R. (1987). Product /Consumption Based Affective Responses and Post Purchase Processes. Journal of Marketing Research, Vol. XXIV (August), 258-270.

84. Westerwick, Silvia. Knobloch., Mothes, Cornelia., and Polavin, Nick (2020). Confirmation Bias, Ingroup Bias, and Negativity Bias in Selective Exposure to Political Information. Communication Research 47(1) 104-124.

85. Wheeless, L.R. (1974). The effects of Attitude, Credibility and Homophily on Selective Exposure to Information. Speech Monographs, 41, 329-328.

86. Yang, Liu. (Cathy)., Toubia, Olivier., \& Jong, Martijn. G. de. (2018) Attention, Information Processing, and Choice in Incentive-Aligned Choice Experiments. Journal of Marketing Research, 55(6), 783-800.

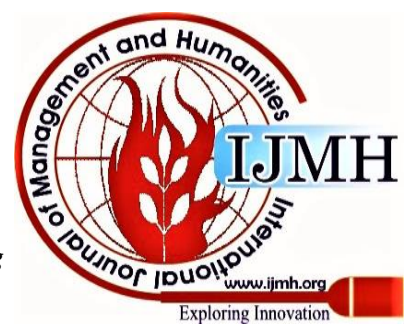




\section{AUTHORS PROFILE}

Dr. Ruchika Sachdeva, is a Doctorate in Marketing and a Master's in Business Administration. She has a teaching experience at under Graduate and Graduate level for teaching management and marketing students. She works as an adjunct faculty at Jack Welch College of Business and Technology, Fairfield, USA. Her teaching experience includes Principles of Marketing, Consumer Behavior, Advertising, Services Marketing. Her main area of research is Consumer Behavior, Branding, Advertising, and Marketing ethics. Dr. Ruchika's publications have been in the field of brand extension, information processing, and factors influencing consumer decision making. 